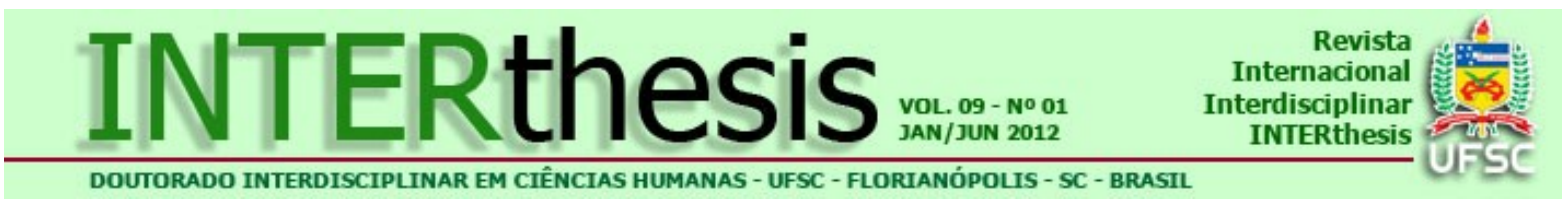

\title{
JUVENTUDE E BIOPOLÍTICA: O PODER JOVEM ENQUANTO OBJETO DE INTERVENÇÃO POLÍTICA
}

\section{YOUTH AND BIOPOLITICS: THE YOUNG POWER AS AN ISSUE OF POLITICAL INTERVENTION}

\section{JUVENTUD Y BIOPOLÍTICA: EL PODER JOVEN COMO OBJETO DE INTERVENCIÓN POLÍTICA}

\section{Marcos Vinicius da Silva Goulart ${ }^{1}$ Nair Iracema Silveira dos Santos ${ }^{2}$}

\begin{abstract}
RESUMO:
Problematiza-se neste artigo, a partir da Psicologia Social, como e em função de quais razões os jovens foram vistos como objeto estratégico de intervenção política global, a partir da década de 1980. Analisando documentos oficiais da Organização das Nações Unidas e outros produzidos no Brasil, sob um referencial genealógico inspirado pelo trabalho filosófico de Michel Foucault, investigou-se uma área tensa que são as práticas direcionadas aos jovens, especialmente os discursos que prescrevem políticas públicas, nos quais eles são tratados como um grupo populacional e, ao mesmo tempo, um grupo politicamente relevante para o progresso social. O poder jovem aparece, aqui, como um analisador importante que visa refletir sobre uma maneira de encarar a força da juventude que, por um lado é considerada incontrolável e, por outro é canalizável, podendo ser utilizada como um recurso estratégico para os países em desenvolvimento. A pesquisa sinalizou que há um deslocamento importante na problemática dos jovens, mostrando que não é mais a força política contestadora que está em jogo, mas uma força positiva que visa ao desenvolvimento político e social e, por conseguinte, esse é o objetivo estratégico das ações governamentais que visam melhorar a vida da população em geral.
\end{abstract}

Palavras-chave: Juventude. Políticas públicas. Biopolítica. Poder.

\section{ABSTRACT:}

This paper addresses, from the perspective of Social Psychology, the issue of how and why youth has up till recently been thought of as a strategic object for global political intervention since the 1980's. Through a Foucault-inspired genealogical analysis of some of the United Nations' official documents, as well as of specifically

\footnotetext{
${ }^{1}$ Mestre em Psicologia Social e Institucional pela Universidade Federal do Rio Grande do Sul (UFRGS). E-mail: mvinicius.goulart@gmail.com

Doutora em Educação pela Universidade Federal do Rio Grande do Sul (UFRGS). E-mail: nair.iracema@gmail.com
} 
Brazilian data, we inquire into an intricate subject-matter: the youth-oriented practices, and particularly those discourses prescriptive of public policies. Through such practices and discourses, young people come to be referred to both as a sort of population group and a politically relevant one as far as social progress is concerned. The concept of young power emerges in the present inquiry as a significant analytic device fitting to work out a way of envisaging the force of youth - since, on the one hand, this force is often thought to be of a quite unworkable sort; on the other hand, though, it can undergo some focusing, thus serving as strategic resort to the interests of the developing countries. Our research so far points to an important shift in the youth issue, showing that youth's contestatory political force is no longer at stake, but rather its positive force aiming at political and social development. Consequently, this is the strategic goal of governmental efforts to the effect of increasing people's overall standard of living.

Keywords: Youth. Public policies. Biopolitics. Power.

\section{RESUMEN:}

En este artículo se busca problematizar, desde una mirada de la Psicología Social, como los jóvenes fueron constituidos como objeto estratégico de la intervención política global. Analizando documentos oficiales de la Organización de las Naciones Unidas y otros producidos en Brasil, bajo un referencial genealógico inspirado por el trabajo filosófico de Michel Foucault, investigamos las prácticas direccionadas a los jóvenes, en especial los discursos que prescriben políticas públicas, en los cuales son considerados como un grupo poblacional y, al mismo tiempo, como un grupo políticamente relevante para el progreso social. El poder ejercido por los jóvenes aparece aquí como un analizador importante que busca reflexionar sobre la manera de encarar el poder de la juventud que, por un lado, es incontrolable y, por otro, es canalizable, pudiendo ser utilizada como un recurso estratégico para los países en desarrollo. Nuestra pesquisa ha señalado que hay un desplazamiento importante en la problemática de los jóvenes, demostrando que no es más la fuerza política contestadora que está en juego, pero sí una fuerza positiva que busca el desarrollo político y social y, por consiguiente, este es el objetivo estratégico de las acciones gubernamentales que tienen como meta la mejora de la vida de la población en general.

Palabras-clave: Juventud. Políticas públicas. Biopolítica. Poder.

\section{INTRODUÇÃO}

Este artigo analisa como e em função de quais razões os jovens foram vistos como objeto estratégico de intervenção política global. Ele é parte de uma pesquisa de mestrado do primeiro autor, desenvolvida no Programa de Pós-Graduação em Psicologia Social da UFRGS, que analisou a juventude como um problema de políticas públicas. O poder jovem, uma espécie de força presente na juventude, que, nas décadas de 1960 e 1970, era visto como um elemento de contestação política importante, em meados da década de 1980, começa a ser posto em xeque a partir 
de uma série de ditos e interditos que reconfiguram a rebeldia dos jovens. Há um declínio do movimento estudantil e a emergência de uma noção de juventude como um padrão de consumo e força a ser utilizada, canalizada.

Nesse sentido, os discursos sobre uma juventude, objeto de política pública específica, são discutidos neste artigo, a partir de documentos oficiais da Organização das Nações Unidas e do Governo Brasileiro, de matérias publicadas em revistas e jornais, e de pesquisas que desenvolveram uma reflexão sobre a juventude brasileira, especialmente obras de Poerner (1979) e de Foracchi (1972/1982). O poder jovem, considerado um analisador, será aqui problematizado como um discurso que opera em determinada época, pondo em relação um corpo de enunciados descontínuos sobre a juventude. Não se trata de postular a existência de um poder substancial, o que iria de encontro a nossa orientação metodológica, mas sim de certa força que os discursos atribuem ao jovem, seja ela contestadora a um sistema político, positiva para o desenvolvimento social ou algo a ser controlado.

A análise proposta se dá a partir de um referencial foucaultiano, visando tratar dos discursos "[...] enquanto práticas que obedecem a regras" (FOUCAULT, 2007, p. 157). Ora, essas regras são o conjunto de ditos e interditos que se relacionam diretamente em uma prática social, produzindo sujeitos, estratégias, objetos ou conceitos. Tratar os documentos dessa forma é perceber neles relações que extrapolam a própria letra do texto, não havendo, por conseguinte, nada a ser interpretado por trás dos discursos. É preciso tratar os documentos como elementos de uma trama em que, ao dizer-se algo, explicita-se, em parte, uma relação de forças que é extremamente produtiva: os ditos e interditos expressos nos discursos dizem respeito àquilo que foi feito ou fazemos cotidianamente.

Falar em ditos ou interditos é levar em consideração que esta pesquisa tem como eixo da análise do discurso aquele que é chamado por Michel Foucault de genealógico, isto é, como uma reflexão crítica que procura apreender o discurso "[...] em seu poder de afirmação, [...] não um poder que se oporia ao poder de negar, mas o poder de constituir domínios de objetos, a propósito dos quais se poderia afirmar proposições verdadeiras ou falsas" (FOUCAULT, 1996, p. 69). Isso significa que é necessário conceber aquilo que se diz sobre algo como um dito que materializa relações complexas, em que objetos e sujeitos são elaborados e 
proposições acerca deles são produzidas. Deste ponto de vista, os ditos que fazem parte de determinado discurso, seriam enunciações que produziriam a trama social, numa correlação com os interditos, isto é, com aquilo que não deve ser enunciado, pois corresponde a coisas que devem ser execradas de um domínio discursivo.

No caso específico do conceito de juventude, é contraproducente o estabelecermos antes da análise proposta, pois é preciso dar vida a esse conceito a partir do solo tenso dos documentos, na relação que estabelecem com enunciados concebidos como positividade, como materialidade, compreendendo que o que chamamos de ditos e interditos são elementos que compõem uma trama social, em que ao dizer-se algo os objetos são formados (FOUCAULT, 2007). Assim, não há um conceito de juventude que orienta a presente pesquisa, mas uma análise que, em função do que é dito e do que não deve ser dito, estabelece a sua emergência. Ademais, o objetivo deste trabalho não é formular um conceito de juventude, e sim analisar certas condições em que os jovens foram se transformando em objeto de intervenção política, objeto traçado em um campo de forças em que saberes formulavam uma maneira de encarar políticas públicas, condutas e a própria experiência juvenil. Assim, como pretendemos demonstrar, observam-se relações de saber/poder em que aspectos culturais, sociológicos e psicológicos da juventude são realçados, indicando olhares sobre esse objeto e, consequentemente, induzindo um modo de intervenção sobre ela: dos estudos sobre os jovens, passa-se à ação política, que visa conduzir a juventude enunciada como problemática a uma situação controlável em termos de população. Neste contexto, a juventude será considerada objeto de políticas públicas na perspectiva biopolítica, conforme os estudos de Michel Foucault (1999/2008).

Foucault apresenta a noção de biopolítica como um segundo eixo do biopoder (poder sobre a vida, biologicamente considerada), diferenciando-a do poder disciplinar, que incide sobre corpos individuais. No plano da biopolítica serão corpos populacionais, como conjunto de viventes, e os problemas destes advindos: saúde, higiene, natalidade, mortalidade, raça, longevidade. Assim, analisa-se "[...] um conjunto de processos como a proporção dos nascimentos e dos óbitos, a taxa de reprodução, a fecundidade de uma população, etc" (FOUCAULT, 1999, p. 290). A biopolítica seria um conjunto de intervenções políticas e governamentais que visariam um controle da vida populacional. Temos o surgimento da estatística, 
conhecimento do Estado, também conhecida como aritmética política (FOUCAULT, 2006), que no encontro com a Economia Política, se torna Ciência Política. Podemos dizer, assim, que a ação, do ponto de vista dos Governos, não vai ser apenas sobre os indivíduos em si mesmos, um tipo de orientação do poder disciplinar, porém sobre os indivíduos subsumidos em uma população.

A biopolítica será aqui entendida como conjunto de práticas que tem como alvo a população jovem, o controle de suas condutas e a gestão de suas vidas, tendo o Estado como principal operador desta, quando se intensifica a formulação e execução de políticas públicas direcionadas à juventude.

Iniciamos o artigo analisando alguns discursos do ano de $1985 \mathrm{com}$ o intuito de compreender uma reconfiguração do poder jovem, que deixa de estar ligado a um ideal contestador e passa a ser visto como um ideal de consumo e cultural. $\mathrm{Na}$ sequência, analisamos como os discursos sobre a rebeldia da juventude serviram como base para outra forma de encarar a problemática dos jovens, abrindo espaço para uma visão mais "positiva" a partir da interdição da relação direta entre juventude e movimento estudantil. Por fim, analisamos como alguns discursos da Organização das Nações Unidas (ONU) serviram como base para a orientação do Governo Brasileiro no que diz respeito às políticas públicas de juventude.

\section{A FORÇA DA JUVENTUDE: REPENSANDO UMA HISTÓRIA}

O ano de 1985 foi marcado por significativas mudanças políticas e culturais no Brasil. De início, temos a eleição indireta à presidência da república de Tancredo Neves, sepultando de vez o governo militar que desde 1964 comandava o país. Além disso, no mesmo período dessa efervescência democrática, temos no Rio de janeiro um evento cultural que não só vai marcar uma geração, como vai ressignificar uma noção de juventude: o Rock In Rio. Há também outro elemento importante nesse mesmo período, e que parece tangenciar ambos os fatos, que é um suposto declínio do movimento estudantil brasileiro, do qual a rebeldia característica parecia não estar em sintonia com os novos ares democráticos, ou seja, as noções de juventude e de estudante destoam, abrindo espaço para uma noção mais múltipla e, ao mesmo tempo, menos rebelde de juventude. 
Em relação ao Rock In Rio, é preciso ressaltar que Roberto Medina, o idealizador desse grande empreendimento cultural, criou não somente um megaevento, mas uma marca que, em certo sentido, formulou uma maneira de repensar a juventude brasileira. Este evento era uma utopia, o símbolo de uma juventude que se "libertava" e de um Brasil que se modificava. Entretanto, essa utopia, esse lugar ideal, foi materializado em um grande centro comercial, de modo que os jovens do "rockódromo" ${ }^{3}$ eram vistos como consumidores de música, de cigarro, de fast-food, de cerveja, etc. Em função disso, o que poderia haver de rebelde naquela juventude era apenas o excesso e a extravagância, enunciados que irão se repetir tanto no discurso do declínio do movimento estudantil, quanto em uma pesquisa de publicidade que iremos analisar no decorrer do texto.

O idealizador do Rock In Rio, com seu tino publicitário, foi considerado um exemplo de empreendedor, que ousou, em um momento de grande crise econômica, convencer grandes empresas a investirem seu capital nesse mega show, que contava com o maior palco do mundo montado até então, uma aparente contradição, um exagero intempestivo diante de uma cruel recessão econômica. Apesar disso, em uma entrevista à Revista Veja, que o denominou de "o anfitrião da juventude", Roberto Medina reconheceu que o clima político no Brasil foi determinante para a viabilização do seu "negócio utópico" de 11 milhões de dólares, justificando que "a eleição de Tancredo Neves devolve a esperança para todo mundo" (MEDINA, 1984, p. 8), trazendo boas expectativas políticas que soltaram os freios do mercado.

Esse bom ar dos novos tempos, explicitado pelo Rock In Rio em sintonia com redemocratização do Brasil, situa também a juventude como uma espécie de força revigorante, algo que se deve ter e levar em consideração, uma espécie de bom senso, potência e renovação. É o que podemos constatar ao relacionar o Rock In Rio com a fala de um carnavalesco do Rio de Janeiro:

A festa nacional que foi a vitória de Tancredo Neves e as multidões adolescentes que se reuniram no Rock In Rio trouxeram uma poderosa carga de eletricidade ao país, fazendo com que os sambistas e as escolas aceitem um desafio inédito - incorporar a energia da juventude e dos novos tempos a seus desfiles (PINTO, 1985, p. 114).

3 Expressão utilizada na época que fazia referência ao local onde aconteceria o Rock In Rio.

R. Inter. Interdisc. INTERthesis, Florianópolis, v.9, n.1, p. 305-333, Jan./Jul. 2012 
Podemos constatar, com isso, que a força da juventude é algo que precisa ser canalizada estrategicamente, no que diz respeito ao carnaval, seria usar essa potência da juventude para ser a escola campeã. $O$ título do texto do qual foi extraído o trecho citado acima é "Do rockódromo ao sambródromo", que tem um significado prático interessante, pois ambos se referenciam. Segundo o dicionário Houaiss (2009), a palavra "sambódromo" foi criada em 1984 por Darcy Ribeiro, vicegovernador do Rio de Janeiro, para designar o espaço projetado por Oscar Niemeyer onde aconteceriam os desfiles das escolas de samba e, eventualmente, outros espetáculos. Se pensarmos no que foi dito pelo carnavalesco, a partir da composição das palavras, perceberemos que o sambódromo deveria transformar-se em "rockódromo" e, retornando a si mesmo, se tornaria jovem, revigorado, eletrizante.

A reivindicação do carnavalesco, incitando as escolas de samba a se modernizarem, incorporando a energia da juventude presente no Rock In Rio é, por conseguinte, uma conciliação entre dois movimentos culturais e musicais aparentemente antagônicos, o rock e o samba. Mas isso não é o mais importante, o fundamental disso tudo é que a reivindicação do carnavalesco traz em si um pedido de reatualização, sintonia com os novos tempos e, no caso do carnaval, uma conjunção entre modernidade e tradição, consequentemente, podemos dizer que juventude neste campo discursivo é também conciliação, também é comunhão.

Para se ter uma noção do impacto do Rock In Rio no Brasil, basta pensarmos na entrevista de Roberto Medina citada anteriormente, em que ele diz que convidou Tancredo Neves para comemorar a sua eleição no "rockódromo", mas o presidente apenas sorriu, desdenhando, aparentemente, o convite (MEDINA, 1984). Porém, menos de um mês depois, parece que, indiretamente, o presidente the respondeu. Quando perguntado em uma entrevista sobre o que achava daquela juventude esperada para mega show carioca, Tancredo disse: "A minha juventude, por quem eu tenho apreço, respeito e admiração, não é a do Rock in Rio. [...] É a do estudo, do trabalho, do sofrimento, da luta". (TANCREDO..., 1985, p.29). Esse fato foi noticiado e classificado como um "Passo em falso" (PASSO..., 1985), revelando uma discrepância entre o novo tempo político, representado pela figura do futuro presidente, e parte das transformações culturais daquele tempo. 
É possível constatar que a fala de Tancredo Neves representava um discurso que via na juventude uma força positiva para a nação, desde que inserida no mercado de trabalho, ligada à escola, à busca por emprego, em sintonia com um país que, aparentemente, voltava a ser democrático e precisava desenvolver-se social e economicamente. Entretanto, essa redemocratização brasileira possibilitou também a emergência de um tipo de juventude que negava aquela visão ideal do presidente, mas que, em certo sentido, era produzida por um discurso publicitário comercial. Dessa maneira, temos um novo presidente com um velho discurso, contestado pelos jovens roqueiros do Rock In Rio e pela mídia que, desde um ponto de vista, endossava esse discurso juvenil. É o poder jovem que novamente entra em cena, o retorno de um discurso que, nas décadas de 1960 e 1970, também gerava discussões acaloradas sobre o potencial libertador da juventude, mas, é claro, com diferenças significativas.

Na década de 1960 e 1970 a rebelião da juventude era concebida como a manifestação de uma força histórica e social materializada no movimento estudantil. A problematização do objeto juventude se dava no sentido de entender essa revolta como uma resposta à crise de um sistema opressor e injusto. Essa perspectiva é tanto trabalhada por Poerner (1979) quanto por Foracchi (1972/1982), embora, pelo menos para a segunda, essa força da juventude seja de certa forma latente na sociedade, sendo transformadora em vista do rumo incerto para qual ela levava. Logo, não é algo do qual se pode usar, pois não pertence ao jovem em si, mas o atravessa: "É o poder real que expressa uma tendência concreta, que traduz uma resposta 'espontânea' à crise, mas cujos rumos continuam indefinidos, não podendo prever aonde nos conduzirão [...]" (FORACCHI, 1972, p. 105).

Em 1985, de outra forma, esse poder jovem reconfigurava-se. Não estava estritamente ligado a uma força política contestadora do sistema, mas sim, a um ideal cultural e comercial: era algo que podia ser produzido, ouvido no rádio, comprado nas lojas e visto em programas de televisão. A emissora de televisão Rede Globo, para se ter uma ideia, tendo os direitos de transmissão do Rock In Rio, usava como slogan, em 1985, a sugestiva frase: "Rede Globo 20 anos, a alegria de ser jovem com você" (CORDEIRO, 2006). Assim, o poder de contestação da juventude não seria mais um problema, pois não explicitaria uma crise social, uma 
denúncia contra o sistema. Diferentemente, a juventude, com o Rock In Rio, celebrava uma nova situação política, sem crises.

\section{A REBELDIA COMO COMPREENSÃO DO OBJETO JUVENTUDE}

Em 1984 uma agência de publicidade chamada McCann-Erickson elaborou uma pesquisa para conhecer melhor o perfil da juventude brasileira, adotando, por definição, como jovem, aquela pessoa que pertence à faixa etária de 15 a 24 anos. A pesquisa foi publicada pela Revista Veja em 1984, sendo celebrada como um dos maiores estudos sobre a juventude brasileira até então, mostrando um resultado surpreendente: os jovens do país, em sua maioria, não eram tão rebeldes assim, pelo contrário, eles eram muito mais conservadores do que se imaginava. Segundo a pesquisa, a juventude, em sua maioria,

[...] condena a infidelidade conjugal. Condena o homossexualismo. Tem dúvidas sobre se o aborto deve ou não ser liberado. E, quanto à educação que vem recebendo, embora ache que às vezes os pais se metem demais na vida dos filhos, afirma que não tem outro modelo a oferecer [...] (A VOZ..., 1984, p. 52).

Ora, essa descrição é uma espécie de conclusão, mostrando que os jovens brasileiros preferem os valores ditos estabelecidos. Nessa pesquisa, cinco perfis de jovens foram analisados, a saber, o jovem integrado, o jovem contestador, o jovem conservador, o jovem moderno e o jovem independente. Não cabe aqui explicar cada um dos perfis ou a maneira como eles foram delimitados, tampouco os fundamentos epistemológicos da pesquisa. Não é essa a questão para a análise aqui proposta, estamos tomando-a como um documento material, atravessado por um discurso acerca da juventude e constituído por enunciados que se repetem em outros documentos. Por outro lado, também não queremos discutir os aspectos ideológicos do texto, embora reconheçamos o viés muitas vezes reacionário desta revista, porém, consideramos os dados explicitados, referenciados em uma pesquisa sociológica que serve para esta matéria, e que é exaltada como a maior já desenvolvida no Brasil sobre este tema.

Em relação aos perfis de jovens apresentados, um deles nos chama a atenção, visto representar os jovens "[...] portadores daquela rebeldia a que se acostumou associar a juventude" (A VOZ..., 1984, p. 53), o "jovem contestador", que em relação ao total dos jovens pesquisados, correspondia a $5 \%$. O perfil "jovem 
conservador" correspondia a $23 \%$ do total da amostra da pesquisa, demonstrando, estatisticamente, que ligar jovem a rebeldia representava um desconhecimento acerca da juventude. Os dados são categóricos, o perfil "jovem contestador", diz respeito a uma minoria quando relacionado à totalidade da amostra da pesquisa.

Um perfil interessante de se analisar é o "jovem integrado", que diz respeito ao jovem trabalhador, que é pobre e que só quer melhorar a sua condição social e econômica. Assim como o "jovem conservador", o "jovem integrado" é completamente adaptado ao sistema, porém, ele "[...] é competitivo e individualista, sua grande aspiração é subir na vida" (A VOZ..., 1984, p. 52). Se, por um lado, o "jovem conservador" é aquele que está em sintonia com a moralidade e educação que recebeu dos seus pais, sendo, também, tímido e retraído; por outro lado, o "jovem integrado" é empreendedor, deseja ter uma vida melhor sem depender de ninguém, pensando somente em si mesmo, como afirma a pesquisa. Desse modo, tanto o "jovem conservador", quanto o "jovem integrado", representam a total afinidade com as condições morais, sociais e econômicas do país, sendo uma parcela significativa da amostra da população jovem pesquisada, que, somada aos três outros perfis, permite a Revista Veja anunciar: "Uma pesquisa com jovens de 15 a 24 anos mostra que eles formam um grupo mais variado e bem menos rebelde do que se imagina" (A VOZ..., 1984, p. 52). Esse anúncio tem a sua importância na medida em que desconsidera um elemento importante da análise sociológica sobre juventude no Brasil na década de 1960 e 1970, em que a rebeldia era um elemento fundamental. A correlação de forças entre sistema opressor e juventude era um objeto de problematização, ou seja, o ethos rebelde da juventude servia como um analisador.

Em 1968, por exemplo, Artur José Poerner escreveu um livro chamado "O poder jovem: história da participação política dos estudantes brasileiros", em que, entre outras coisas, pretendia demonstrar que "o movimento estudantil brasileiro é a forma mais adiantada e organizada que a rebelião da juventude assume no Brasil" (POERNER, 1979, p. 47). Isso significa que o autor via a rebeldia do jovem como algo político ligado a uma maneira de se organizar; entretanto, o par juventude/rebeldia, se materializava na figura do estudante universitário, isto é, estudante e poder jovem eram as duas faces de uma mesma moeda. Segundo o autor, era na constituição de si enquanto estudante, que o jovem vivenciaria na 
prática, a potência contestadora da juventude, tendo em vista que o papel do estudante não era apenas estudar, mas se rebelar contra um sistema velho e reacionário.

Por outro lado, Foracchi (1972), indo um pouco além de Arthur Poerner, fala o seguinte sobre o movimento estudantil:

Ele próprio define-se como oposição incontrolável ao sistema de poder, reconhecendo, outrossim, que a peculiaridade da condição estudantil the outorga perspectivas de luta não compartilhadas por outros movimentos de oposição. (FORACCHI, 1972, p. 109).

Podemos perceber que o movimento estudantil tem um papel importante nas análises apresentadas. Esse poder jovem materializado na figura do estudante é tido como uma potência de se opor, mas não por mera rebeldia ou contestação. Pelo contrário, essa energia juvenil é uma força que desvela o sistema em crise, não sendo meramente uma luta do novo contra o velho, e sim, uma "[...] força social, possuidora de um poder potencial [...]" (FORACCHI, 1972, p. 99). É por essa razão que o jovem, na figura do estudante, tinha um papel social relevante para os autores citados. É claro que, no caso deles, havia uma diferença entre jovem e estudante, porém, era na correlação de ambos que a contestação juvenil tinha a sua relevância.

Não podemos negar, contudo, que o tema da luta de classes estava muito presente na análise dos dois autores, como se o jovem universitário fosse o oprimido numa luta entre senhores e escravos e, ao mesmo tempo, nas devidas proporções, a juventude uma vanguarda revolucionária. A leitura de Marialice Foracchi "[...] é evidentemente inspirada nas discussões sobre o problema da organização do proletariado, nas divisões possíveis de um movimento, na articulação entre sua base e seus militantes" (MORTADA, 2009, p. 380). Consequentemente, no movimento estudantil o jovem adquiriria a sua consciência de classe, aprenderia a se organizar e se articular com outras frentes de luta contra o sistema. A autora, além disso, fala de uma consciência jovem, que seria a "[...] expressão dos conflitos e tensões que se desenvolvem no sistema e que são extravasados nos movimentos de juventude" (FORACCHI, 1972, p. 12). Portanto, essa consciência, essa figura até certo ponto "transcendente" às práticas, mas que se atualiza nelas, é uma força de explicitação da crise que, sendo uma reconfiguração da noção de consciência de classe, tem um papel fundamental no processo de entendimento da rebelião da juventude dos anos 1960 e 1970. 
Essa força instituidora de uma crise, todavia, não é algo a ser utilizado por alguém. Ao contrário, ela é uma forma de compreender a juventude no interior de um campo prático. A própria Marialice Foracchi nos dá uma pista para entendermos a problematização da juventude em seu tempo: "Afinal, não tem cabimento indagar o que está acontecendo com essa juventude, e sim investigar o que está acontecendo com essa sociedade, que produz jovens que a rejeitam tão fortemente" (FORACCHI, 1982, p. 28). Isto significa que o poder jovem é uma resposta social que atravessa os movimentos estudantis, materializando-se na contestação política dos jovens.

No livro de Artur Poerner (1979) percebe-se uma crítica social em que a contestação dos jovens, do ponto de vista do movimento estudantil, é um prelúdio de uma revolução, uma tomada de posição que deixa de "[...] ser um simples conflito para se transformar em rebelião social da juventude [...]" (POERNER, 1979, p. 38). O sentido dessa revolta dos jovens era o seu papel histórico, era uma classe que emergia no movimento estudantil, uma energia que incorporava a luta do povo oprimido brasileiro: eram os estudantes que sabiam o que estava acontecendo no contexto político nacional e internacional, cabia a eles tomar a frente dessa luta. A rebeldia contestadora dos jovens, na visão de Arthur Poerner, tinha um papel político importante no desenvolvimento social brasileiro daquele período.

Esse olhar que via na rebeldia da juventude um papel político importante, pelo fato de explicitar a crise social do país, perdia o terreno em meados da década de 1980. É isso que vemos quando voltamos àquela pesquisa do perfil da juventude que estávamos analisando. O interessante é que esse jovem, universitário, participante do movimento estudantil se transforma numa piada, numa caricatura. A juventude a qual ele pertence não diz respeito a uma força, um poder de resposta, a explicitação de uma crise social. Pelo contrário, esse tipo de jovem é:

[...] de família de posses, mas vota preferencialmente no Partido dos Trabalhadores e, para seu meio de transporte, gostaria mais, por exemplo, de um jipe do que do automóvel caro que o pai tem na garagem. Consumidor que não entra nos modismos, é tão radical que evita o uso de relógio digital. Avesso à propaganda, desconfia até dos cigarros de baixo teor. Critica o regime, a família, a moral - tudo (A VOZ..., 1984, p. 52).

A pesquisa cria um perfil caricato, o "jovem contestador", que, além de ser um sujeito contraditório, pois está ligado politicamente a um partido que, historicamente, lutou pelos trabalhadores e pela população menos favorecida, ao mesmo tempo faz parte de uma classe de famílias abastadas - os próprios opressores dos pobres. 
Isso quer dizer que esse "jovem contestador" não deve ser levado em conta enquanto força política e, tampouco, como consumidor. Essa rebeldia é esvaziada do conteúdo militante, se transformando em mero rótulo, uma imagem que não se sustenta, não explicitando uma crise social, mas sendo ela própria um contrassenso.

Em 1985 a revista "Desvios" publicou um interessante dossiê sobre o movimento estudantil, analisando o seu declínio enquanto força política relevante, demonstrando que a reivindicação das entidades representativas dos estudantes não correspondia à realidade brasileira. Além disso, não poderíamos mais falar daquele poder jovem ligado ao movimento estudantil como uma força espontânea, pois ele era "controlado" por estratégias políticas bem delimitadas. Os "jovens contestadores" tinham uma cara - isso pode ser visto nas gravuras tanto da pesquisa publicada na Veja, quanto no dossiê que estamos citando -, eles eram barbudos, amantes da maconha, de Chê Guevara e outros elementos que costumeiramente ligamos aos jovens de esquerda. É claro que o declínio da força do movimento estudantil das décadas anteriores não está ligado apenas a isso, mas sim, a vários fatores, entre eles, e esse parece ser o mais importante, a politização partidária do movimento.

O fato é que ao estar ligado ao movimento estudantil, o jovem estaria assinando o seu atestado de "incompetente político", sendo, de uma forma ou de outra, utilizado por forças político-partidárias maiores, pois "ser estudante tornou-se isto: ser o corpo, a carne bruta para que uma aristocracia aja e pense em seu nome, para que busque em seu nome os objetivos dela" (RIBEIRO NETO, 1985, p. 66). Ora, é possível perceber, aqui, que há uma descontinuidade relevante para a nossa análise, qual seja, a ruptura radical em relação ao discurso que considerava a força dos estudantes um poder jovem de transformação política e social. Os estudantes, no interior do movimento estudantil, não são mais os agentes transformadores da história, mas, uma espécie de massa com pouco peso político e social.

Essa visão um pouco pessimista do movimento estudantil contrasta com uma visão um pouco mais crítica. Segundo Paoli (1985), o que emerge nesse declínio do movimento estudantil não é o fim daquela força contestadora dos estudantes. Ao contrário, é uma negação do modelo representativo e uma abertura para outras práticas políticas. O ME, como era chamado o movimento estudantil em sua formalidade, enquanto entidade representativa distanciou-se da realidade dos jovens 
estudantes. O que é importante nisso tudo, não é que eles fossem vítimas indefesas da burocracia partidária, e sim, que a minoria representada pelo "jovem contestador", no interior dos movimentos estudantis, deixou de pensar-se apenas como jovem e estudante, relacionando a sua problemática a outras lutas sociais dispersas pela sociedade. Assim, é preciso analisar esse suposto declínio do movimento estudantil como uma crise importante, valorizando a "[...] coragem de perder os pontos de apoio míticos, a obrigação de sair do isolamento, a anuência em deixar emergir a experiência cotidiana como reflexão política coletiva" (PAOLI, 1985, p. 60). O que há, portanto, é uma nova articulação do poder jovem que, desvinculando-se dos estudantes, passa a ser uma força social mais dispersa, ligada a uma complexidade de relações de poder que emergem naquele contexto.

Podemos dizer que, segundo a autora, o ME teria que deixar de se ver apenas como $\mathrm{ME}$, repensar as suas práticas não somente como luta dos estudantes, mas ir além, abrir-se para um novo universo político que estava aflorando. No que diz respeito ao movimento dos estudantes, enquanto entidade representativa, via-se uma enorme discrepância entre o mundo real e as suas plataformas políticas. Isto quer dizer que o que os jovens estudantes queriam talvez não fosse a mesma coisa que os outros jovens não estudantes queriam. Portanto, o ME não tem mais o monopólio da juventude. Desse modo, por exemplo, o título dado por Artur Poerner (1979) ao seu livro, que de alguma forma exaltava a União Nacional dos Estudantes (UNE), seria questionável pelo fato de tratar estudantes e jovens como correlatos diretos. A vida estudantil seria apenas uma forma muito particular, entre outras tantas, de se vivenciar a experiência juvenil.

A pesquisa sobre o perfil da juventude brasileira, que já citamos, enuncia justamente esse movimento em que os jovens ligados ao ME, com a sua força contestadora, são tomados como um perfil específico e minoritário. Os $5 \%$ de jovens que pertencem ao perfil "jovem contestador" nos indicam que não é mais possível falar em movimento estudantil e juventude como se fosse quase a mesma coisa. Assim, percebe-se uma espécie de liberação da juventude em relação à noção de estudante. De outro modo, os ditos que questionaram tanto o que se entendia por jovem rebelde, dizendo que, ao contrário, os jovens eram conservadores, operam como uma espécie de interdição do discurso sobre o poder jovem enquanto força política relevante para a mudança da sociedade. É como se, em linhas gerais, fosse 
dito: os jovens não são mais rebeldes, eles querem trabalhar, acham que a educação que receberam dos seus pais é correta e são muito individualistas.

O declínio do movimento estudantil enquanto força política e contestadora representa, também, um declínio de uma noção de juventude. A rebeldia característica dessa noção ganha outras roupagens e, em certo sentido, desloca-se para outras concepções mais variadas, conforme a abordagem dada. Quando se falar em ação política que tem os jovens como objeto, a rebeldia "[...] não deve ser vista como algo a ser combatido, mas sim, sob o ângulo positivo, como força mobilizadora e construtiva" (ADAMO et al., 1985, p. 17). Em outra concepção, a rebeldia também vai ser vista como uma espécie de porta para a delinquência juvenil, uma violência contra a ordem em função de uma "[...] dolorosa búsqueda de identidad" (ONU, 1987b, p. 75). Temos aqui, por ora, mais duas concepções de rebeldia que se ligariam a uma maneira de compreender a juventude na década de 1980.

Juventude, como vimos, deixa de ser um correlato direto do Movimento Estudantil. Ela se libera dessa concepção e passa a ter uma dimensão mais diversa, esvaziando, ao mesmo tempo, o caráter político que a ligava a uma força política transformadora. A rebeldia, agora, quando pensada em relação aos jovens, vai ser também um perfil de consumo, uma maneira de a publicidade lidar com essa parcela da população, um objeto estatístico pertencente à determinada faixa etária. No entanto, se pensarmos na forma dispersa em que esse discurso da rebeldia foi se reformulando, surgem outras configurações, outras problematizações.

A energia rebelde da juventude pode ser pensada como uma força positiva a ser canalizada estrategicamente, mas, apesar disso, essa mesma energia rebelde pode ser vista como um passo para a delinquência juvenil, como veremos a seguir. Nesses dois casos, há uma relação direta, na medida em que sem o controle "positivo" da rebeldia, a delinquência se faria presente. Não obstante, a interdição da rebeldia da juventude dos anos de 1960 e 1970, bem como a sua dispersão em outras práticas sociais para além do movimento estudantil, é uma das condições de possibilidade desses discursos sobre a força da juventude da década de 1980: o poder jovem se torna palatável, controlável e bom.

Cabe agora adentrarmos em outro campo para pensarmos em como um conceito de juventude foi formulado a partir de estratégias de intervenção sobre a 
população jovem mundial. Isso servirá para compreendermos melhor como a juventude foi pensada em um contexto de crise global, bem como refletir sobre outra visão de jovem que vemos aparecer. Enfim, é somente no interior das políticas públicas voltadas aos jovens, a partir de um esvaziamento político do objeto juventude (em seu "divórcio" com o movimento estudantil) que vemos surgir um tipo específico de jovem no interior de um contingente populacional.

\section{UM DISCURSO GLOBAL SOBRE A JUVENTUDE: NAÇÕES UNIDAS E BRASIL}

No dia 17 de dezembro de 1979, a Assembleia Geral da Organização das Nações Unidas, designou, através da resolução 34/151, que o ano de 1985 seria o "Ano Internacional da Juventude: Participação, Desenvolvimento, Paz" (ONU, 1987a). Os seis anos que transcorreram entre a proclamação em assembleia e o ano propriamente dito eram o indício de que aconteceria uma série de encontros e preparações para o ano de celebração da juventude mundial. Nesse contexto, a situação dos jovens nos países "menos desenvolvidos" era objeto de constantes análises a fim de entender melhor os processos em que esse grupo populacional estava inserido. Ora, foi preciso delimitar um objeto, estabelecer um conceito e direcionar as análises a uma juventude que precisava ser traçada diante um cenário de crise global, em que o desemprego crescente, o endividamento externo, a redução do crescimento econômico e o aumento do número de pessoas em estado de pobreza absoluta afetavam um grande número de países (ONU, 1984).

No que concerne aos jovens,

En los últimos años se ha convertido en un lugar común señalar que los jóvenes son especialmente vulnerables a los efectos de la crisis social y económica mundial. Outro lugar común es sostener que debe integrarse eficazmente a los jóvenes en el proceso de desarrollo para superar la crisis mundial y sus manifestaciones regionales, nacionales y locales (ONU, 1987b, p. 12).

A partir disso, podemos perceber dois aspectos para a análise da situação da juventude mundial na década de 1980. Primeiramente, os jovens eram considerados, a partir de dados demográficos, os que mais sofriam com a crise econômica e social mundial. O interessante, ao analisar o documento citado, é que, do ponto de vista da vulnerabilidade social, o recorte populacional era muito preciso: ser jovem era pertencer à faixa etária de 15 a 24 anos e, ser vulnerável à crise 
mundial, a partir desse recorte etário, era pertencer ao conjunto populacional dos países mais pobres. Em 1984, segundo dados da ONU (1987b), por exemplo, a partir da faixa etária em questão, de cada cinco jovens no mundo, quatro pertenciam aos países "menos desenvolvidos". O que demonstrava que o contingente populacional juvenil, em alta densidade, representava um problema para esses países.

Por outro lado, ao analisar as maneiras de enfrentar essa crise juvenil mundial, foi preciso pensar em uma noção de juventude um pouco mais flexível, a fim de superar a arbitrariedade do recorte por faixa etária e a sua relação direta com a vulnerabilidade social a partir das estatísticas demográficas. Ora, neste caso, ser jovem não era apenas pertencer à faixa etária de 15 a 24 anos, mas, também, afirmar sua própria identidade e seus interesses. Contudo, como já vimos, para chegar a essa conclusão, foi preciso pôr em dúvida qualquer noção de juventude que se amparasse nos movimentos estudantis das décadas de 1960 e 1970. Sendo assim, o movimento estudantil e os estudantes - palavras que tinham um significado de protesto e luta - não serviam mais para dar conta dessa nova noção "positiva" de juventude, pois os movimentos estudantis, além de dizerem respeito apenas a jovens urbanos e de classe média, não propuseram alternativas viáveis e coerentes às instituições que eles questionavam (ONU, 1987b). Segundo este ponto de vista, aquela força do jovem de afirmar a sua identidade e seus interesses, era justamente a que deveria ser capitalizada para o desenvolvimento dos países pobres. Esse poder que os jovens têm de saber o que querem deveria ser "potencializado"; portanto, os jovens "[...] cuyas energías habían de canalizarse positivamente" (ONU, 1987b, p. 9), deveriam ser integrados ao processo de desenvolvimento econômico e social mundial, abrindo mão daquela rebeldia de outrora, sinal de imaturidade dos jovens universitários que se voltavam contra sistemas de ensino e políticos de forma inconsistente.

Outro ponto fundamental da análise elaborada pelas Nações Unidas é a diferenciação entre uma abordagem psicobiológica e sociológica acerca da juventude, de modo que ser jovem seria "un sistema de actitudes y una pauta de conducta relacionados con una determinada posición en la sociedad" (ONU,1987b, p. 11). Sem desconsiderar uma noção psicobiológica de juventude (ligada à puberdade e transformações comportamentais), as propostas da ONU priorizam 
uma noção social ligada ao papel do jovem na sociedade. Porém, essa definição carregaria um problema, qual seja, para cada tipo de configuração social haveria um tipo de juventude. Essa diversidade de processos de socialização juvenil representaria um problema, pois eliminaria a possibilidade precisa de delimitar uma juventude objeto do estudo e de ações a serem prescritas pela ONU.

Entretanto, embora se reconheça em um primeiro momento uma diversidade de experiências juvenis,

[...] la definición de juventud como la edad comprendida entre los 15 y los 24 años ofrece, pese a algunas limitaciones, cierta utilidad estadística, así como la conveniencia práctica de contar com una herramienta analítica definida para examinar la compleja red de diferencias regionales y nacionales (ONU, 1987b, p. 11).

Assim, se pensarmos a partir dessa simplificação analítica, tal qual explicitada na definição da ONU, perceberemos uma redução dos diversos modos de socialização a um recorte preciso e bem definido em relação à população mundial. Significa dizer que toda a análise da situação da juventude, tendo como saber privilegiado os dados estatísticos, constituiria uma parcela da população a ser objeto de avaliações, estudos e ações políticas com a finalidade de resolver o problema dos jovens no mundo. Contudo, a população jovem nos países "menos desenvolvidos" - como a ONU se referia - não é um problema pelo fato de esse grupo pertencer a um suposto conceito de juventude ou constituir-se como segmento jovem; mas sim à relação que pode ser expressa em uma série enunciativa jovem, pobreza, vulnerabilidades e subdesenvolvimento.

Não obstante, reelaborar um conceito de juventude, superando toda uma fragmentação teórica e metodológica, era uma das finalidades do Ano Internacional da Juventude, sendo uma noção estratégica que serviria para "[...] facilitar la dinámica de la participación de los jóvenes, particularmente en el desarrollo, y en la sociedad en geral" (ONU, 1987b, p. 12). Além disso, é preciso levar em consideração que dados estatísticos serviam como um alarme para o problema dos jovens no mundo. Na América Latina, por exemplo, mais especificamente na Argentina, dos jovens entre vinte e vinte e quatro anos, em 1982, 46\% estavam desempregados (ONU, 1987b). Nesta pesquisa analisada, há pouquíssimos dados sobre o Brasil. Porém, pode-se perceber uma inclinação de, a partir de alguns países, generalizar a situação para toda a América Latina. Esses dados evidenciam 
uma tendência comum na época, a saber, chamar a atenção para problemas graves que a população mundial pode sofrer num futuro próximo.

Temos aqui dados que relacionam juventude a problemas sociais que devem ser enfrentados. Para isso, elaboram-se pesquisas que visam pensar características específicas de determinado grupo em relação à população em geral. Isso significa que há, nesse contexto, um esforço político de controle global e, consequentemente, algo que pode ser visto sob um viés biopolítico, pois a partir de análises sobre a situação da população jovem no cenário de crise apontado pela ONU, várias ações reguladoras são indicadas, especialmente aos países pobres e aqueles em desenvolvimento. Um exemplo é o que chamam de "justiça para menores", que englobaria "[...] una amplia variedad de métodos correctivos del uso indebido de drogas, la delincuencia y los pequeños delitos" (ONU, 1987b, p. 73). Enfim, temos aqui uma proposta que visa salvaguardar toda população dos possíveis problemas relacionados à criminalidade.

Segundo Popkewitz, "o raciocínio populacional como pensamento social produziu novas formas de individualidade na qual a pessoa é definida normativamente em relação a agregados estatísticos [...]" (1994, p.189). Ora, podemos dizer que dentro da perspectiva das prescrições da ONU, ao fundamentarse a partir de estatísticas demográficas, se estabelece um sujeito jovem que emerge a partir da sua relação com a totalidade da população. Mesmo assim, embora haja um recorte etário (15 a 24 anos), aparentemente arbitrário, ele tem uma importância, pois situa, em relação à sociedade, uma periodização entre o final da infância e o acesso ao mundo do trabalho (ONU, 1987b), justamente um período em que, de alguma forma, um sujeito pode ser considerado economicamente ativo, isto é, produtivo do ponto de vista do desenvolvimento econômico.

Pensando a partir desse ponto de vista, uma noção importante a ser pontuada, e que já apareceu no nosso texto, é a de vulnerabilidade social. Ela está diretamente ligada à ideia de risco, nesse caso, vulnerável é aquela pessoa que está sujeita a alguma situação desfavorável do ponto de vista social e, consequentemente, econômico. Ora, se levarmos em conta a juventude que é objeto de políticas públicas, o que está em jogo é a ação sobre um grupo em que é "[...] maior a possibilidade da ocorrência de algum dano, fazendo-se necessária a intervenção sobre o perigo, deslocando-o de uma ordem do imponderável e 
tornando-o passível de previsão e controle" (HILLESHEIM; CRUZ, 2008, p. 196). Desse modo, pensar em uma juventude vulnerável é projetar o seu futuro, intervindo nos riscos do presente com a finalidade de se evitar problemas posteriores. Quando se fala em vulnerabilidade, do ponto de vista das políticas públicas, portanto, estamos falando de uma previsão e de uma prescrição de ações efetivas sobre a vida atual de determinado grupo juvenil. Não se questiona se a ONU está correta em adotar certa perspectiva epistemológica ou não, o que queremos salientar é que esse recorte etário pautou pesquisas, estabeleceu condutas de Estados e formou um objeto. Ou seja, é um recorte com certa positividade, tendo em vista a sua repetição em muitos documentos posteriores - inclusive no Brasil. Em suma, a noção de população jovem em questão possui uma materialidade e é isso que nos interessa.

Esse discurso global sobre a juventude ecoa no Brasil, ele reaparece no documento de conclusão do "Projeto Juventude", organizado pelo Instituto Cidadania em 2004 após uma série de seminários, encontros e oficinas. Primeiramente, o instituto adotou a mesma noção de juventude da ONU, identificando o grupo populacional pelo recorte de faixa etária. O documento destaca como referência importante aquela ideia de que os jovens vivenciam uma diversidade de problemas, mas, ao mesmo tempo, são parte da esperança da nação, como podemos ver nesse trecho do documento:

\footnotetext{
Os jovens ocupam o centro de questões que comovem o país, tanto no que diz respeito aos problemas gerados pelo agravamento das desigualdades, como no que se refere à esperança de novos caminhos para nossa evolução social, com valores e padrões éticos superiores aos que predominam hoje. (INSTITUTO CIDADANIA, 2010, p. 10).
}

Ora, quem lesse esse trecho na década de 1980 não estranharia o que é pautado aqui: a relevância dos jovens em função de ser uma parcela da população com certa importância estratégica, na qual a sociedade deposita as suas maiores esperanças, apesar de vivenciar as maiores crises sociais e econômicas. Não há nada por trás dessa sintonia entre o discurso da Organização das Nações Unidas e o documento final do Instituto Cidadania, o que há é a adoção propositada de certa maneira global de encarar a problemática da juventude, isto é, em grande parte, o discurso da ONU é aderido pela pesquisa brasileira, como é explicitado no documento: 
Um pequeno grupo executivo do Projeto Juventude foi a campo para complementar esse circuito de interlocuções e para solicitar oficialmente a colaboração de instituições importantes como a Unesco, o Programa das Nações Unidas para o Desenvolvimento, a Unicef, a Organização Internacional do Trabalho, o Fundo das Nações Unidas para a População e diversas ONGs reconhecidas por seu trabalho na área (INSTITUTO CIDADANIA, 2010, p. 106).

Essa relação que fizemos entre o documento do Instituto Cidadania e o discurso prescritivo da ONU desde a década de 1980 serve para ilustrar uma maneira comum de encarar a problemática da juventude. Isso também significa que há uma forma comum de problematizar o tema, de estabelecer proposições verdadeiras acerca dele, de constituir um sujeito que pode falar sobre ele, apontando soluções e estratégias. O mais interessante é que esse documento é uma das bases das discussões sobre políticas públicas de juventude que temos atualmente, representando um texto chave para a compreensão das estratégias de ação sobre a população jovem no Brasil.

Indo mais longe, Souza (2009) diz que:

No caso específico do Projeto Juventude, há que se lembrar que o processo de participação dos jovens (e não jovens) foi orientado por uma ONG especialmente criada para a proposição de políticas públicas (e cuja principal liderança foi eleita Presidente da República em 2002), e que havia definido o tema juventude como prioridade de trabalho para os anos 2003 e 2004. Ou seja, o Projeto Juventude já nasceu no interior de um determinado discurso sobre juventude e políticas públicas (SOUZA, 2009, p. 14).

Podemos perceber uma conexão entre o Projeto Juventude e a orientação das Nações Unidas acerca da temática da população jovem mundial. Além disso, a autora situa este projeto como fundamental na constituição das políticas públicas de juventude atualmente, aprofundadas durante o governo do presidente Luiz Inácio Lula da Silva, do Partido dos Trabalhadores, que iniciou no ano de 2003. Nesse sentido, ela tem razão, visto muitas proposições internacionais terem sido acatadas pelo Governo Federal, bem como aquele discurso em que a juventude é vítima dos problemas econômicos e sociais e, ao mesmo tempo, solução e esperança de futuro. Assim sendo, os jovens têm uma força a ser cultivada em seu próprio benefício, colaborando também para o desenvolvimento de toda a população. No Manual do Educador do Programa Projovem ${ }^{4}$ Urbano (BRASIL, 2009), o Projeto

\footnotetext{
${ }^{4}$ Programa Nacional de Inclusão de Jovens: Educação, Qualificação e Ação Comunitária, criado em 2005 pelo Estado brasileiro e que, em 2007, incorporou o "Consórcio Social da Juventude", o "Juventude Cidadã" e o "Escola de Fábrica", constituindo-se, assim, como PROJOVEM Integrado. Ele
} 
Juventude é citado na bibliografia pelo menos duas vezes, significando que, o documento do Instituto Cidadania tem a sua importância, sendo mais um elemento do saber governamental sobre a juventude atualmente.

É preciso levar em consideração que esse saber é constituído a partir de uma crítica às ações governamentais voltadas à juventude no Brasil desde a década de 1990, introduzindo uma noção mais "positiva" de jovem, defendendo a sua autonomia e participação na constituição de políticas públicas para seu segmento. Um texto importante que aborda esse tema se chama "As Políticas Públicas e a Juventude dos Anos 90" de Maria das Graças Rua (1998), em que a autora fala que grande parte das ações políticas estatais voltadas aos jovens, analisadas durante os anos de 1990, eram ações pontuais, voltadas para insatisfações sociais, sem compor uma agenda governamental. As políticas direcionadas aos jovens eram ações de emergência que, atingindo diversas camadas da população, atingiam a juventude também. Além disso, "a maior parte das ações reflete a concepção típica do primado da economia: são propostas de correção de desvios e sequelas. Não chegam sequer a expressar concepções de prevenção de problemas [...] (RUA, 1998, p. 742).

Ora, o que está em jogo é a defesa de políticas públicas específicas para os jovens brasileiros. Na perspectiva da autora, os jovens não podem ser tratados como uma parte qualquer da população. Eles são um público especial com problemas singulares, que devem ser prevenidos a partir de ações governamentais específicas. Desse modo, é preciso reorganizar essas ações, repensá-las a partir de uma noção estratégica de juventude a fim de torná-las mais eficiente. Há, a partir disto, uma espécie de reorganização da problemática da juventude e, ao mesmo tempo, um processo de institucionalização dessa abordagem. Como afirma Marília Sposito:

Os novos organismos assumem, predominantemente, o caráter de assessorias, embora em algumas situações sejam criadas secretarias de estado ou coordenadorias, e são definidos pela sua vocação maior: articular e assegurar uma certa transversalidade nas suas ações sob o ponto de vista do aparato público e, ao mesmo tempo, assegurar uma interlocução com os segmentos juvenis (SPOSITO, 2003, p. 69).

compreende quatro modalidades, a saber, o "Projovem Urbano", o "Projovem adolescente", o "Projovem Trabalhador" e o "Projovem Campo". 
Esse trecho nos leva a crer que nesse debate sobre a juventude no contexto das ações políticas, delineia-se uma concepção que vê nos jovens condições de atores sociais, com vontades próprias, reivindicações, lutas e propostas. Eles deixam de ser apenas meros objetos de políticas públicas, mas sim, interlocutores para ações em que eles próprios são os alvos. Ganha visibilidade um discurso da diversidade dos modos de se vivenciar a juventude e, ao mesmo tempo, a defesa de um tratamento do jovem como um sujeito de direito que, por assim ser, tem a sua especificidade em relação ao conjunto total da população. Ele não deve, ademais, ser um simples receptor de ações políticas, que veem na juventude, em certas circunstâncias, um problema a ser resolvido. Nada disso! O jovem, necessariamente, tem que ser concebido como uma pessoa com o direito de dispor de bens e serviços assegurados pelo Estado.

Em 2004 é elaborada uma proposta de Plano Nacional de Juventude ${ }^{5}$, um documento propositivo que visa dar conta de uma concepção de política pública para os jovens brasileiros. Essa concepção de política carrega consigo uma concepção de juventude, que vivencia uma problemática singular que é a sua própria condição. Ele afirma que "[...] a dificuldade de inserção no mercado de trabalho é percebida pelos jovens como principal componente negativo de sua condição juvenil junto ao tema da violência" (BRASIL, 2004, p. 20). Assim, é nessa vontade de "escutar" os jovens que vai se introduzir uma série de estratégias para lidar com a sua problemática.

Em relação à violência, em 2004, a UNESCO lançou o "Mapa da Violência IV", que era um estudo do impacto da violência na vida dos jovens, uma pesquisa demográfica que visava entender essa condição juvenil a partir da população jovem do país, tendo como finalidade

[...] promover uma discussão mais ampla ao reconhecimento das causas da violência, a criação de mecanismos institucionais de expressão e diálogo, e sobretudo, contribuir para a formulação de políticas públicas que possam dar respostas concretas a um tema que afeta a nossa juventude (WERTHEIN; SENNA; MIRANDA, 2004, p. 8).

Temos aqui outro documento que se propõe a elaborar uma pauta de ações políticas voltadas aos jovens no Brasil. Porém, esse documento parte de dados demográficos que utilizam como indicadores estatísticos a mortalidade juvenil. $O$

\footnotetext{
${ }^{5}$ Projeto de Lei $n^{\circ} 4.530$ aprovado pela Comissão Especial de Políticas Públicas para a Juventude do Congresso Nacional em 2004, ainda em tramitação em outras instâncias.
}

R. Inter. Interdisc. INTERthesis, Florianópolis, v.9, n.1, p. 305-333, Jan./Jul. 2012 
número de homicídios de jovens, em relação ao conjunto total da população, era preocupante, tendo em vista que, "no ano de 2002, para o país como um todo, $39,9 \%$ das mortes de jovens devem-se a homicídios. E essa proporção vem crescendo de forma acelerada nos últimos anos. Na população não jovem essa proporção é só de 3,3\%" (WAISELFISZ, 2004, p. 161). É importante dizermos que a pesquisa desenvolvida considera jovens aqueles que pertencem à faixa etária de 15 a 24 anos, e não jovens aqueles que pertencem à faixa etária abaixo de 14 anos e acima de 25 anos. Há aqui, portanto, um recorte preciso, uma população jovem vulnerável à violência que aumenta e tende a aumentar ainda mais.

A pesquisa da UNESCO, como vimos, tem um propósito, que é estabelecer um saber que colabore na implantação de políticas públicas para os jovens brasileiros, porém, não é de qualquer jovem que se está a falar. Fala-se de um jovem estabelecido a partir de dados estatísticos, que em relação à mortalidade juvenil, em função do conjunto total da população brasileira, representa um problema grave ao corpo populacional. A conclusão do documento, não obstante, é um pouco mais otimista, investindo na possibilidade de se pensar ações governamentais mais consistentes:

E os caminhos dessa discussão não são difíceis de delinear: dever-se-á procurar promover políticas e estratégias que estimulem a plena inserção e um papel protagônico para os jovens, que se articulem esforços e iniciativas do setor público, seja federal, estadual ou municipal, da esfera privada, das organizações não governamentais e das dos próprios jovens. Estratégias que promovam o conhecimento, a revalorização e o fortalecimento de identidade juvenil e sua participação, como setor ativo e consciente, a construção da cidadania e no desenvolvimento do país (WAISELFISZ, 2004, p. 166).

O autor parece estar em consenso com os documentos que visualizam nas políticas públicas para a juventude uma solução para o problema dos jovens. Se por um lado os jovens representam, quando a partir de um recorte populacional, um problema, por outro, eles são a própria solução, deve-se investir no poder jovem, deve-se fazer junto com eles e, ao mesmo tempo, estudá-los sistematicamente: entender os seus códigos, as suas maneiras de agir, as suas atuações políticas específicas. Isso tudo nos leva a crer que a noção de jovem estabelecida como alvo de políticas públicas é extremamente específica, embora se defenda uma diversidade de modos de se vivenciar a juventude. Entretanto, o tipo de jovem que emerge no contexto do "Mapa da Violência" é o mesmo que aparece no Projeto 
Juventude do Instituto Cidadania? Em suma, quem são e onde estão os jovens considerados objeto de políticas públicas?

\section{CONSIDERAÇÕES FINAIS}

Quando decidimos falar em um poder jovem que é alvo de políticas públicas no Brasil, sabíamos que estávamos adentrando em um terreno em disputa, em que órgãos governamentais e não governamentais incentivam reflexões sobre o tema, destinando recursos financeiros para diversas pesquisas que tenham como princípio problematizar a questão juvenil. Além disso, é importante levarmos em consideração o grande interesse de organismos ligados ao sistema das Nações Unidas, que desde a década de 1980, pelo menos, elaboram planos, programas e financiam propostas de ações políticas voltadas aos jovens de todo o mundo.

De um lado, pudemos perceber algumas estratégias que começavam a pensar a juventude como um poder a ser conduzido e utilizado para o desenvolvimento social, mas, também, como um poder comercial, isto é, os jovens também eram consumidores com suas especificidades, havendo, não obstante, certa diversidade de se vivenciar esse tipo de juventude. Por outro lado, o papel político dos jovens também era posto em questão, tendo em vista que eles representavam uma força importante para o desenvolvimento político e social no Brasil. A rebeldia, nesse caso, não pode ser pensada como o modelo de uma época, havendo uma rebeldia contestadora das décadas de 1960 e 1970 e outra das décadas de 1980, 1990 e 2000. Ao contrário, há uma descontinuidade em relação ao papel político da juventude, os ditos que interditavam certo discurso acerca da rebeldia, nada mais faziam do que dizer que o poder jovem não deveria ser algo espontâneo que aponta para incertezas e outras possibilidades imponderáveis, mas sim, algo importante a ser desenvolvido, canalizado, cultivado, utilizado.

No caso do poder jovem enquanto explicitação da crise social, temos uma potência que desvela o sistema e demonstra a sua verdade enquanto contradição. Ele é uma participação política que atravessa o movimento estudantil, tendo a sua especificidade no correlato jovem/estudante. Ora, na década de 1980 esse tipo de participação política é posta em xeque, o declínio do movimento estudantil anuncia que há outras maneiras de atuação política, outros tipos de práticas e modos de 
vivenciar a juventude, não havendo um sistema em crise a ser desvelado. A crise, de alguma forma, deu lugar a outras formas de ação: os jovens estão para além do movimento estudantil, o poder jovem pode ser vendido, comprado, visto na televisão. Logo, a "alegria de ser jovem" se divorcia dos estudantes.

Essa discussão acerca da juventude não pode deixar de levar em consideração que a constituição dos jovens como objeto de políticas públicas deve extrapolar o tema da participação social destes. Igualmente, se levarmos em consideração os documentos que traçam o perfil dos jovens, podemos perceber que a defesa de sua participação e de sua autonomia não é o fator mais relevante. $O$ que importa nisso é o quanto esses jovens podem contribuir ao desenvolvimento social do país, a sua liberdade deve ser vista como consequência de uma problematização sobre os problemas sociais, ou seja, a possibilidade da autonomia está na conquista ou no resgate da cidadania, que aparecem aqui como correlatas.

No entanto, o jovem que é objeto de políticas públicas atualmente não é qualquer jovem, não podemos dizer que há uma simples continuidade entre aquela juventude do Rock In Rio ou do poder jovem da década de 1960 e 1970. O que há é um deslocamento do objeto. No fundo o que interessa nas intervenções políticas por parte de órgãos oficiais ou não oficiais não é o poder jovem enquanto força política de contestação, e sim, a juventude que representa um problema para todo o resto da população. Os jovens se transformam em um recorte populacional e são subsumidos em números, dados, amostras, probabilidades e previsões: uma biopolítica da juventude. 


\section{REFERÊNCIAS}

A VOZ da maioria. Veja, n. 818, p. 52-60, 9 mai. 1984.

ADAMO, F. A. et al. O problema da juventude não é a juventude, mas os fenômenos políticos, econômicos e sociais que a condicionam. In: ADAMO, F. A. et al (org.). Juventude: trabalho, saúde e educação. Rio de Janeiro: Forense Universitária, 1985. p. 11-52.

BRASIL. Comissão Especial de Políticas Públicas para a Juventude . Plano Nacional de Juventude. 2004. Disponível em:

$<$ http://www.camara.gov.br/sileg/Montarlntegra.asp?CodTeor=253927>. Acesso em: 23 nov. 2009.

BRASIL. Presidência da República. Secretaria Nacional de Juventude. Projovem Urbano: Manual do Educador, Orientações Gerais, 2009. Disponível em: $<$ http://www.projovemurbano.gov.br/userfiles/file/materialdidatico/educador/guias/Ma nual_Orientacoes_Gerais.pdf>. Acesso em: 25 jan. 2010.

CORDEIRO, L. Cazuza Muito Doido - Entrevista a Leila Cordeiro - Rock in Rio. Janeiro de 1985. Disponível em:

<http://www.youtube.com/watch?v=uj2_cg0tQdI\&NR=1>. Acesso em: 16 fev. 2011.

FORACCHI, M. M. A juventude na sociedade moderna. São Paulo: Pioneira, 1972.

FORACCHI, M. M. Você é contra a juventude? In: FORACCHI, M. M. A participação social dos excluídos. São Paulo: Editora Hucitec, 1982. p. 25-31.

FOUCAULT, M. A ordem do discurso: aula inaugural no Collège de France pronunciada em 2 de dezembro de 1970. São Paulo: Edições Loyola, 1996.

FOUCAULT, M. Em Defesa da Sociedade: Curso no Collège de France (1975 1976). São Paulo: Martins Fontes, 1999.

FOUCAULT, M. A tecnologia política dos indivíduos. In: In: MOTTA, M. (Org.) Ética, Sexualidade, Política: Ditos e Escritos V. Rio de Janeiro: Forense Universitária, 2006. p. 301-318.

FOUCAULT, M. A Arqueologia do Saber. Rio de Janeiro: Forense Universitária, 2007.

FOUCAULT, M. Segurança, Território, População: Curso no Collège de France (1977 - 1978). São Paulo: Martins Fontes, 2008.

HILLESHEIM, B.; CRUZ, L. R. da. Risco, vulnerabilidade e infância: algumas aproximações. Psicologia \& Sociedade, Porto Alegre, v. 20, n. 2, ago. 2008. 
Disponível em: <http://www.scielo.br/scielo.php?script=sci_arttext\&pid=S010271822008000200006\&lng=pt\&nrm=iso >. Acesso em: 21 nov. 2010.

HOUAISS, A. Dicionário Houaiss da Língua Portuguesa. Rio de Janeiro: Objetiva, 2009. [versão online].

INSTITUTO CIDADANIA. Projeto Juventude: Documento de Conclusão. 2004. Disponível em: <www.interagir.org.br/politica/boletim/arquivos/projetojuventude.pdf>. Acesso em: 13 jan. 2010.

MEDINA, R. Anfitrião da juventude. Veja, n. 818, 12 dez. 1984b. p. 5-8.

MORTADA, S. P. De jovem a estudante: apontamentos críticos. Psicologia e Sociedade, Florianópolis, v. 21, n. 3, dez. 2009. Disponível em: $<$ http://www.scielo.br/scielo.php?script=sci_arttext\&pid=S010271822009000300011\& $\underline{\text { lng=en\&nrm=iso }}>$. Acesso em: 02 set. 2010.

ONU. Declaración de Mexico sobre población y desarrollo. In: CONFERENCIA INTERNACIONAL DE POBLACIÓN, 1984, Nova York. Anais... Nova York: ONU, 1984. p. 1-4.

ONU. Assessment of the impact of measures and activities accomplished during the Internacional Youth Year: Participation, Development, Peace (1985). Nova York: ONU, 1987a.

ONU. Situación de la juventud en el decenio de 1980 y perspectivas y problemas para el año 2000. Nova York: ONU, 1987b.

PAOLI, M. C. Movimento estudantil hoje - apresentação. Desvios, Rio de Janeiro, n. 4, p. $61-71,1985$.

PASSO em falso. Veja, n. 853, 9 jan. 1985.

PINTO, F. Do Rockódromo ao Sambódromo. Veja, n. 857, p. 114, 6 fev. 1985.

POERNER, A. J. O poder jovem: história da participação política dos estudantes brasileiros. Rio de Janeiro: Civilização Brasileira, 1979.

POPKEWITZ, T. S. História do currículo, regulação social e poder. In: SILVA, T. T. (Org.). O Sujeito da Educação: estudos foucaultianos. Petrópolis: Editora Vozes, 1994. p. 173-210.

RIBEIRO NETO, A. Um laço que não une mais. Desvios, Rio de Janeiro, n. 4, p. 6171, 1985.

RUA, M. G. As políticas públicas e a juventude dos anos 90. In: CNPD. Jovens acontecendo na trilha das políticas públicas. Brasília: CNPD, 1998. p. 731-749.

SOUZA, R. M. Protagonismo juvenil: o discurso da juventude sem voz. Revista 
Brasileira Adolescência e Conflitualidade, São Paulo, n.1, 2009. p. 1-28.

SPOSITO, M. Trajetórias na constituição de políticas públicas de juventude no Brasil. In: FREITAS, Maria Virgínia de; PAPA, Fernanda (Org.) Políticas Públicas: juventude em pauta. São Paulo: Cortez, 2003. p. 57-75.

TANCREDO condena 'Rock in Rio'. Folha de S. Paulo, São Paulo, ano 64, n. 20364, p. 29, 03 jan. 1985.

WAISELFISZ, J. J. Considerações finais. In: WAISELFISZ, J. J. Mapa da Violência IV: os jovens no Brasil. Brasília: UNESCO; Instituto Ayrton Senna; Secretaria Especial de Direitos Humanos, 2004. p. 161-166.

WERTHEIN, J.; SENNA, V.; MIRANDA, N. Apresentação. In: WAISELFISZ, J. J. Mapa da Violência IV: os jovens no Brasil. Brasília: UNESCO; Instituto Ayrton Senna; Secretaria Especial de Direitos Humanos, 2004. p. 7-8.

Artigo:

Recebido em: 28/07/2011

Aceito em: 27/03/2012 